\title{
Márgenes del archivo. Historia editorial de un motín
}

(4) Facundo Ruiz

Universidad de Buenos Aires - Conicet, Argentina

Fecha de recepción: marzo 2021 Fecha de aceptación: mayo 2021

\begin{abstract}
Resumen
La obra de Carlos de Sigüenza y Góngora (1645-1700) puede distinguirse como la de una literatura cuya forma no encuentra su estilo. Y su estilo por eso, a lo largo de los siglos, ha desestabilizado su impresión (ecdótica y crítica), planteando preguntas que todavía hoy esperan respuestas. De ello, notablemente, da cuenta Alboroto y motín de los indios de México: en su escritura, en las lecturas de que fue objeto, en el sujeto de escritura que proyecta y, muy especialmente, desde su primera impresión en 1929. De ello también da cuenta la "incidencia de edición", ese problema crítico.
\end{abstract}

PALABRAS CLAVE: Sigüenza y Góngora, Alboroto y motín de los indios de México, ecdótica, crítica textual, archivo

\section{File margins. Editorial story of a riot}

\begin{abstract}
The work of Carlos de Sigüenza y Góngora (1645-1700) can be distinguished as a literature whose form does not find its style. That is why its style, over the centuries, has destabilized its impression (ecdotic and critical), raising questions that still await answers today. That is exactly what appears and tells Alboroto y motin de los indios de México: in its writing, in the readings of which it was the subject, in the figure of writing that its projects and, especially, since its first printing in 1929. That is also what shows the "impact of editing", that critical problem.
\end{abstract}

KEYWORDS: Sigüenza y Góngora, Alboroto y motín de los indios de México, ecdotic, textual criticism, archive 


\section{Margens do arquivo. História editorial de um motim}

\section{Resumo}

A obra de Carlos de Sigüenza y Góngora (1645-1700) pode ser distinguida como a de uma literatura cuja forma não encontra o seu estilo. E é por isso que seu estilo, ao longo dos séculos, desestabilizou sua impressão (ecdótica e crítica), suscitando perguntas que ainda hoje aguardam respostas. Alboroto y motín de los indios de México, notavelmente, condensa e expõe tudo isso: na sua escrita, nas leituras de que foi objeto, no sujeito da escrita que projeta e, muito especialmente, desde a sua primeira publicação impressa em 1929. Assim a "incidência da edição", aquele problema crítico, é também fundamental para sopesar y repensar ditas questões.

PALAVRAS-CHAVES: Sigüenza y Góngora, Alboroto y motín de los indios de México, ecdótica, crítica textual, arquivo

Cuando un acontecimiento ocurre fuera de las estructuras del poder, se lo tragan los imperativos de la historia que son en parte los imperativos del mito.

Greil Marcus, El basurero de la historia

Imposible tal vez tras un examen detenido, atento, no obstante algo destella y parece enlazar Alboroto y motín de los indios de México de Carlos de Sigüenza y Góngora con La broma infinita (Infinite Jest) de David Foster Wallace y Elhombre sin atributos (Der Mann ohne Eigenschaften) de Robert Musil. Algo sin duda "fin de siglo", donde el humor existe o resiste quizá a expensas de su gracia, algo sin duda "incontenible", donde la escritura prolifera en moldes que se van deshaciendo con su paso y -sin duda- algo del "(des)orden político", donde todo pareciera estar ocurriendo en paralelo y ser medular-o estar exactamente allí donde nada quedará en pie-, triangulan rápidamente un diálogo que no por imposible resulta menos elocuente. Porque así como Foster Wallace volvía tierra fértil el cementerio donde Hamlet levantaba el cráneo del bufón, su amigo, Yorick (a fellow of a infinite jest) y George Steiner parafraseaba -torpemente, aclara, pero con cierta exactitud- el título de Musil (The man whose "I" is in search of his "Me"), el recordado verso de Rubén Darío también podría resumir aquello que destella y enlaza dichas obras o, como mínimo, que describe milimétricamente el conflicto que de punta a punta organiza la literatura de Sigüenza y Góngora, y singularmente Alboroto y motín: "Yo persigo una forma que no encuentra mi estilo".

Sujeto, verbo y objeto -que modalizando el agente no alcanza a estilizarlo- se alinean en México sin conjugarse la tarde del 8 de junio de 1692 y hacen estallar la sintaxis de la relación (informe) al hacerse -quizá inevitable- eco del estallido de un orden (sýntaxis) relativo. Ese estallido conjunto, el de una forma que no encuentra su estilo (hoy no costaría pensar Alboroto y motín como no-ficción si bien entonces interrumpía la lógica que aglomeraba las muy variadas "crónicas de Indias") y un estilo que ha perdido su forma (crisis del régimen Habsburgo para gobierno de su Imperio) es en Alboroto y motín -también y muy especialmente- el resultado de su edición y, nada menos, de su "primera impresión" en 1929, cuando no solo es impreso por primera vez (237 años después de escrito y sin un claro cotejo de las varias copias manuscritas a través de las cuales circulaba desde entonces profusamente) sino impreso en inglés y, para más detalles, como apéndice de una tesis doctoral. Estas múltiples formas de pasaje -de manuscrito/s a impreso, de castellano a inglés, de "relación" (más o menos oficial) a documento (más o menos accesorio)- no hacen en la letra sino enfatizar aquel desequilibrio de la escritura si bien, al mismo tiempo, nos ofrecen una 
"foto" posible, y precisa, de un movimiento -cuanto menos- doble: el de la escritura en la letra y el de la literatura en la historia. Quizá por esto, pocos textos exhiben con más claridad la práctica crítica que supone la labor ecdótica. Pocos textos alientan más a pensar la labor ecdótica como práctica necesariamente crítica. Pues esa labor y esa práctica no solo distinguen con precisión los límites lábiles (escritura, política, informe, sintaxis) del terreno donde Alboroto y motin puede hacer y hace-deshace y rehace- sentido; sino que son ellas, práctica crítica y labor ecdótica, las que hace siglos no dejan de perseguir -medir y reconvertir- el des/encuentro de (su) forma y estilo. ¿Es un documento colonial, una carta de bienvenida a los mexicanos o-sugiere Silva Prada- "un pequeño tratado sobre el motín" (2007: 249)? ¿Es un precursor del periodismo gonzo, autoetnografía de ojos coloniales o, simplemente, nuestro primer "epinicio en prosa" (Moreno, 2018: 92)?

Ciertamente no se trata solo de un efecto de lectura ni, exclusivamente, del modo en el que fue -y en buena medida sigue siendo- editado. Ahí está la figura calidoscópica de Carlos de Sigüenza y Góngora (1645-1700) que, según se mire, es último o pleno "señor barroco" (cfr. Lezama Lima, 1993) y parcial pero primer "sabio" ilustrado (cfr. Leonard, 1984a). Y en ambos casos, curiosa pero quizá no casualmente-como decía su contemporáneo Francisco de Florencia: "archivo animado de doctas y eruditas noticias de aqueste reino" (1685: f.20v). Curiosa pero quizá no casualmente porque esa condición del archivo que señalara Foucault, la de constituirse "a partir de los discursos que acaban de cesar precisamente de ser los nuestros", parece fatalmente adherida a la literatura de Sigüenza y destinarla, desde sus días hasta los nuestros, a formar parte de "la orla del tiempo que rodea a nuestro presente" (2015: 172). En cierto modo, otra vez, una forma que no encuentra su estilo. En Sigüenza se conjugan, y su escritura evidencia una exterioridad insalvable y una ajenidad que, de todos modos, sigue siendo la de nuestro propio lenguaje. Como si cada vez y en cada página volviéramos a encontrar los discursos que acaban de cesar de ser los nuestros. Lo que rodea, sin centro. Lo más reciente de lo que ya no es. Una remanencia que el mismo Sigüenza entendía -martiano literalmente avant la lettre- como "pensión infausta de nuestra América", a la que describía en su Parayso occidental de 1684 como "el que en ella jamás se perfeccione lo que se empieza" (1995: f.18v).

En esa orla del tiempo donde se inscriben su figura y su literatura, Alboroto y motín -ese acontecimiento- no puede sino estremecer singularmente. Porque pensadas siempre a caballo de tiempos que no son el suyo, ya desveladas por un pasado remoto (lo prehispánico) ya pergeñando un futuro remiso (la nación mexicana), su figura y su literatura topan el 8 de junio de 1692 con lo actual, no con la potencia virtual del tiempo (pasado o futuro) sino con su bruta actualidad (presente), esa emergencia: "una relación de fuerzas que se invierte, un poder confiscado, un vocabulario retomado y que se vuelve contra sus utilizadores, una dominación que se debilita, se distiende, se envenena a sí misma, algo distinto que aparece en escena, enmascarado" (Foucault, 1992: 21).

Abrí las ventanas a toda prisa, y viendo que corría hacia la plaza infinita gente a medio vestir y casi corriendo entre los que iban gritando ¡Muera el virrey y el corregidor, que tienen atravesado el maíz y nos matan de hambre!, me fui a ella. Llegué en un instante a la esquina de provincia y, sin atreverme a pasar adelante, me quedé atónito. Era tan en extremo tanta la gente, no sólo de indios sino de todas castas, tan desentonados los gritos y el alarido, tan espesa la tempestad de piedras que llovía sobre el palacio que excedía el ruido que hacían en las puertas y en las ventanas al de más de cien cajas de guerra que se tocasen juntas. (2018: 170)

Domingo 8 de junio de 1692: el descontento por el desigual reparto de trigo y maíz y, sobre todo, por su encarecimiento se suma a las malas cosechas y al dudoso desempeño 
del gobierno virreinal para contener el temor general a la escasez y la especulación económica de ciertos grupos; en la alhóndiga (mercado público que guarda y abastece de granos a la ciudad) se reúne una multitud y, acabado el reparto, por segundo día consecutivo, una india es maltratada, cae muerta y, en andas, la concurrencia avanza con su cuerpo por el centro de la ciudad, primero deteniéndose a las puertas de las casas arzobispales y luego en el Palacio Real que, ante similar falta de respuesta, es apedreado. Poco después comienza el fuego. Como señala Silva Prada, en cualquier caso todo esto fue apenas "las puntas visibles de otros muchos agravios que se infringieron a la población en aquella época" (2007: 380) y, por supuesto, que ese mismo domingo se celebrara la fiesta de Corpus Christi resulta importante, porque "era una de las pocas festividades que lograban incorporar a todos los miembros de la sociedad. Por lo tanto, el hecho de que la ruptura ocurrida en 1692 haya sido precisamente en este día, revela una vez más el significado simbólico de la fiesta y la importancia cuando menos estratégica que los tumultuantes pudieron haberle concedido." (2007: 144) El alboroto se torna motín y el descontento sin promesa, diría Ureña, enhebra uno de los acontecimientos más singulares de la cultura política novohispana, pues si bien "el motín mismo no puede ser pensado como un mecanismo de quiebre de las estructuras coloniales, sino como una fisura que tendía a ser rápidamente reparada" (2007: 511) no faltaron evidencias - como prueba el estudio de Silva Prada- "de un mínimo principio de planificación" (2007: 516), amén de que los "motines del pan", como el de Córdoba (España) en 1652, no siempre quedaron en meras fisuras, como dan cuenta poco más tarde la Revolución francesa y la rusa.

Fisura o ruptura, el 8 de junio de 1692 en la figura y la literatura de Sigüenza irrumpe el desconcierto, un desconcierto efectivamente radical (no la raíz del desconcierto sino el desconcierto raíz) y su ruido y furia -donde estalla una sintaxis posible y una relación establecida- se oye claramente como si "más de cien cajas de guerra tocasen juntas". Y en el centro, en la plaza, se encuentra por eso el pasmo, el disparate original: no un origen absurdo sino lo absurdo de pretenderlo verdadero y único, esencial y no accidental. Como Colón oyendo ruiseñores en las Indias, Sigüenza llega a la plaza de México y no puede sino (des)escribir con "cierta sensación de no estar del todo" (Süssekind, 2000: 29). Pues si al señalar la "pensión infausta de nuestra América" oponía, tan cortés como precavido, "nuestra desgracia a tan heroicos principios" (1995: f.18v) sin precisar a cuáles principios refería (si a los prehispánicos, por donde siempre comenzaba el re-latum de su historia, o a los coloniales, a los que no podía sino endilgar una imagen de orden, violento pero vigente), al vaciar de precisión el origen no duda en subrayar la discontinuidad raigal que lo mantiene unido al presente de nuestra América, impidiendo su perfección toda vez que perfeccionando el vínculo, ese que "nos desune de nuestras continuidades: disipa esa identidad temporal en que nos gusta contemplarnos a nosotros mismos para conjurar las rupturas de la historia; rompe el hilo de las teleologías trascendentales, y allí donde el pensamiento antropológico interrogaba el ser del hombre o su subjetividad, hace que se manifieste el otro, y el exterior" (Foucault 2015: 172). E inscribe por eso, en el comienzo, el azar más irrisorio, la mueca de una identidad:

De esto que instaban, de aquello que oían y de lo del miedo que presumían, y discurrido todo en las pulquerías donde por condición inicua y contra Dios que se le concedió al asentista no entra justicia, ¿qué pudo resultar que nos fuese útil? Acudían a ellas como siempre no sólo indios sino lo más despreciable de nuestra infame plebe y, oyéndoles a aquellos, se determinaba despantar (como dicen en su lengua) a los españoles, a quemar el Palacio Real y matar si pudiesen al señor virrey y al corregidor. Como con esto no les faltaría a los demás que asistían a aquellas pláticas y que no eran indios mucho que robar en aquel conflicto, presumo que se lo aplaudieron (por lo que vimos después). (2018: 159) 
La grotesca escena de la pulquería que Alboroto y motín "presume" al comienzo de la sedición "(por lo que vimos después)", y que no puede sino recuperar la noción estructural de relato como "una aplicación sistemática del error lógico denunciado por la Escolástica bajo la fórmula post hoc, ergo propter hoc" (Barthes, 1970: 20), confirma en la escritura esa discontinuidad original volviendo no solo informe su relación causal sino asincrónica la sintaxis matriz de su relato. Resuena en esta escena otra, también inaugural y grotesca, también callejera y también ocurrida en junio (no el 8 sino el 9) más de dos siglos después: "Tampoco olvido que, pegado a la persiana, oí morir a un conscripto en la calle y ese hombre no dijo: 'Viva la patria' sino que dijo: 'No me dejen solo, hijos de puta'." (Walsh, 2006: 18). En el origen, una vez más, no está la patria sino la injuria, la violencia matriz, el principio chingado: Los hijos de Sánchez.

En este sentido, y especialmente en Alboroto y motín, la pregunta por el archivo (la pregunta del archivo) es -como la forma que no encuentra su estilo- una pregunta por el destino, no por el origen. Una pregunta endémica, que persigue "una historia endémica (...) una historia que habla repetidamente y que repetidamente pierde la voz" (Marcus, 1993: 31). Que es también la historia de la literatura de América, "produciéndose así una simultaneidad impensable en literaturas con una tradición consolidada", una simultaneidad impensable que complica -en sus discontinuidades y asincronías- "el desarrollo lineal de la historia literaria latinoamericana" (Zanetti, 1987: 189). Esa simultaneidad impensable, la que se topa Sigüenza al llegar a la plaza (donde era "tan en extremo tanta la gente, no sólo de indios sino de todas castas"), la que escucha Colón sin estar del todo cierto y atrapan los indios en su red de agujeros, esa simultaneidad impensable que el Inca Garcilaso quiere armonizar con sus Comentarios sabiendo -como dirá luego Cornejo Polar-imposible, como imposible e impensable resulta la simultaneidad de O guesa de Sousândrade y Versos libres de Martí en el infierno de Nueva York, es sin duda "incidencia de lectura" (1987: 180), como planteó señera Susana Zanetti: "la interrelación entre producción y lectura en el interior de la literatura latinoamericana misma" (1987: 178). Pero también, en tanto esa interrelación explica una distinta: la de "un conjunto importante de textos muy especiales, sujetos a la traducción y a su inmersión en ámbitos culturales diferentes a los que pertenecieron" (1987: 180), esa simultaneidad impensable se organiza o explica muchas veces como incidencia de edición. Como sabía Zanetti al detallar "estos desfasajes entre escritura, lectura y relectura" (1987: 184), también los que se producen entre escritura e impresión, entre impresión y reedición, entre edición y lectura, constituyen una literatura y hacen no solo a la lectura y la historia de una literatura sino a las condiciones que ambas trasladan o transforman "como literatura". Esta incidencia de edición opera así, decisivamente, sobre aquella sujeción a la traducción y, más aún, sobre aquella inmersión en ámbitos culturales diferentes, pues la conversión que se opera editorialmente (ecdóticamente) -en su carácter hipotético (cfr. Contini, 1986) o conjetural (cfr. Funes, 1983)- gestiona la cultura en sus diferencias (cfr. Altschul, 2006), que son tanto -y así evidencia Alboroto y motín, como se dijo más arriba- de lengua y tiempo como de género y estilo.

De esta incidencia de edición da cuenta no solo la publicación (manuscrita) y la muy posterior impresión de Alboroto y motín -y, entre ambas, nada menos que su transmisión $-{ }^{1}$ sino, curiosamente, el texto mismo, que en su último párrafo dice:

Este es el estado en que nos hallamos y ésta es mi carta. Si le pareciera a vuestra merced el imprimirla para que en esa corte y en esos reinos sepan todos con fundamento lo que otros habrán escrito con no tan individuales y ciertas noticias, desde luego consiento en ello, presuponiendo el que no se le

1 “cuestión nada simple en la medida en que el texto no posee una existencia ideal fuera de la materialidad del manuscrito, pero tampoco se identifica totalmente con el testimonio que lo transmite” (Funes, 1983: 48). 
añada ni se le quite ni una palabra; y si no fuere de este modo, no salga a luz. Guarde Nuestro Señor a vuestra merced, amigo y señor mío, muy dilatados años y esto con muy perfecta salud y descanso en todo. México y agosto 30 de 1692 años. (2018: 192)

La "merced" de impresión de Sigüenza señala el consentimiento pero no exacta ni formalmente una "petición": Sigüenza no pide, tal cual exigía la legislación entonces vigente (cfr. Fumagalli, 2021), licencia para imprimir su relación sino que expresa cierto asentimiento o, más aún, su deseo de impresión, un deseo que distingue claramente las vías de publicación (manuscrita, impresa) para optar por la estampa de sus palabras pues, como había deseado su contemporánea sor Juana al poeta José Montoro y sus versos ("Dalos a la estampa por que/ en caracteres eternos/ viva tu nombre y con él/ se extienda al común provecho"), también sabía Sigüenza que "En prueba de esta verdad/ mírense cuántos ejemplos/ en bibliotecas de siglos/ guarda el archivo del tiempo" (2014: 122 y 113, vv.333-336 y vv.61-64). Este deseo de impresión, que acompaña toda la escritura de Sigüenza, prácticamente nunca se separa de su limitación material: "Si hubiera quien costera en la Nueva España las impresiones (...) no hay duda sino que sacara yo a luz diferentes obras, a cuya composición me ha estimulado el sumo amor que a mi Patria tengo (...) [pero] jamás tendré con qué poder imprimir[las] por mi gran pobreza", dice en el "Prólogo" de Parayso occidental en 1684 (f. IXr) y todavía en 1700, muerto Sigüenza, se oye su queja en las palabras de su sobrino y albacea, Gabriel López de Sigüenza -en la carta a don Antonio de Aunzibay y Anaya que precede a la primera edición Occidental planeta evangélico, temprano y todavía inédito poema del novohispano: "pues todos saben son grandes los gastos y costos de una imprenta, y hallándose mi tío imposibilitado para hacerlos, ofrecíansele algunas personas a costear, dando lo que fuera necesario, y llegando a tiempo de ejecutarlo faltaban a ello" (1700: f.2). Pero si no se separan, deseo y limitación sí se distinguen, hasta el punto de listar Sigüenza obras que tiene prometidas y "casi escritas" (1684: f. IXr) y confirmar su amigo Sebastián de Guzmán y Córdova, al prologar y costear la publicación de la Libra astronómica y filosófica, escrita casi una década antes: "No sé si es más veloz en idear y formar un libro, que en olvidarlo" (1690: s/f). Sigüenza hace libros permanentemente, les da forma, los idea y "casi escribe"; pero, aunque lo desea con toda intención, no siempre -o casi nunca- los imprime. El deseo de impresión corre así casi indistinguible de su escritura, si bien esta resultó realmente distinta de la letra que, a veces sí y a veces no, pudo contenerla o estamparla. ${ }^{2}$

No obstante, este deseo de impresión en Alboroto y motín es no solo, en caracteres eternos, deseo de archivo del tiempo y sus bibliotecas de siglos sino, inmediatamente, un deseo de "impresión" metropolitana: "para que en esa corte y en esos reinos sepan todos con fundamento". Que sepan todos allá con fundamento y que sepan todos allá con fundamento (de acá) liga sin duda la escritura de Sigüenza a la del Inca en sus Comentarios, esa voluntad de comento y glosa de "lo que otros habrán escrito con no tan individuales y ciertas noticias". Y esa voluntad, que el Inca llamó hacer "relación entera" (2004: 50) y Sigüenza -apenas comenzado Alboroto y motín - historiar con "voz entera" (2018: 117), ciertamente refiere en ambos a la estrategia matriz de no escribir "sin decir cosa que no sea pública y sabidísima" (2018: 117); pero además, singularmente en Sigüenza, al presupuesto de "que no se le añada ni se le quite ni una palabra" al texto propio. La voz entera y el texto entero: ¿cómo conciliarlos? He ahí el problema que Alboroto y motin, desde su escritura, no ha dejado de plantear a sus editores y críticos, que perseguimos -en la letra- esa forma en busca de su estilo. Pues no solo se trata de una deliberada manifestación de intervención de lo público (res publica), esa

2 Parejo con el deseo de impresión y sus limitaciones (que precisa y cataloga Guzmán y Córdova en 169o), va el copioso archivo de Sigüenza y su rápida dispersión, cfr. Burrus, 1959 y Trabulse, 1988. 
voluntad de comento y glosa de historias oficiales, sino -enfáticamente en Alboroto y motín - de una deliberada política de la publicación (imprimirla para que sepan todos), que subraya también una deliberada economía textual de la responsabilidad (no se le añada ni se le quite ni una palabra), autoral e histórica tanto como ecdótica y crítica ( $y$ si no fuere de este modo, no salga a luz).

El deseo de impresión que cierra Alboroto y motín pone en evidencia aquella incidencia de edición. Pues subraya insoslayablemente todo lo que ya en (y desde) la escritura piensa y hace a la letra (impresa) que aún no es pero que espera -quiere y tiende a- ser. En la escritura se ve proyectada (se hace pública) la letra que luego, una vez impresa, publicará (hará visible el proyecto de) una escritura. Sigüenza sabe, y lo dice: prefiere ser impreso, pero no de cualquier manera; porque prefiere ser leído, pero no de cualquier forma; porque el sentido es la construcción conceptual e ingeniosa solo visible en la forma, como se sabía entonces y se leía en Agudeza y arte de ingenio de Baltasar Gracián. Es que ese control del texto impreso, que consciente de la incidencia de edición emerge en el deseo de impresión, es también el costado "material" (el reverso prosaico) de la "poética" de la hidra vocal: si "[e]s como hidra vocal una dicción, pues a más de su propia y directa significación, si la cortan o la trastruecan, de cada sílaba renace una sutileza ingeniosa y de cada acento un concepto" (Gracián, 1943:358), nada más urgente entonces -más aun tratándose de "cosa pública y sabidísima"- que cuidar "el que no se le añada ni se le quite ni una palabra". Pues si como decía Gracián las composiciones antiguas "todo lo echaban en concepto, y así están llenas de alma y viveza ingeniosa" mientras que las modernas "toda su eminencia ponen en las hojas de las palabras, en la oscuridad de la frase, en lo culto del estilo" (1943: 303), requisito indispensable es atender esa eminencia hecha de palabras, frase y estilo, "y-sentencia Sigüenza- si no fuere de este modo, no salga a luz". Pero, como otros tantos testamentarios deseos literarios, esta (última) voluntad del texto se acata pero no se cumple. Y así como Virgilio había pedido quemar su Eneida por encontrarla enmendable e inacabada (Cristóbal, 1992: 25-27), Sigüenza encuentra completa su crónica y pide, por eso, no vea luz si apenas una palabra, de más o de menos, viniera a inacabarla.

Es cierto que la frase termina superponiendo metafóricamente ("no salga a luz") lo que al inicio -materialmente- se ocupó de distinguir ("ésta es mi carta", manuscrita; aquel mi deseo, de "imprimirla"); pero también es cierto que la historia editorial de Alboroto y motín se ocupó en confirmar su presunción o certeza, la de un desencuentro raigal (por unas palabras de más o de menos, y casi siempre por bastante más de una, o bastante menos) de aquella voz entera y su impresión acabada. Y de esto, notablemente, da cuenta la primera impresión, ocurrida en el siglo XX y cuya incidencia de edición ha sido altísima y prácticamente nunca revisada. Pues si bien la crónica de Sigüenza, tal cual él sospechaba, tuvo su "éxito" y su público (no solo metropolitano) y todavía hoy siguen apareciendo distintas copias manuscritas (no autógrafas) en bibliotecas y archivos varios -que nadie se ha tomado aún el trabajo de estudiar sistemáticamente-, lo cierto es que exceptuando unos fragmentos incluidos en $D$. Guillén de Lampart. La Inquisición y la independencia en el siglo XVII (1908) de González Obregón, Alboroto y motín se imprime por primera vez en septiembre de 1929 como parte de Don Carlos de Sigüenza y Góngora: A Mexican Savant of the Seventeenth Century de Irving A. Leonard (1896-1996). Y no solo se imprime por primera vez en 1929 y "como parte" de un estudio académico sobre su figura (más que sobre su obra), sino que se imprime -por primera vez- en inglés y como apéndice documental. Son estas coordenadas las que organizan y fundan, crítica y ecdóticamente, la fortuna editorial de la crónica de Sigüenza. Coordenadas fundamentales y en buena medida fundacionales (pues fue Leonard quien alentó y organizó los estudios sobre la figura del novohispano así como la recuperación sistemática de su obra y archivo) serán ellas no solo las que finalmente "sacarán a luz" al texto sino las que -decisivamente- enfocarán y reflejarán, oscurecerán y refractarán, en él lecturas posibles. 
En este sentido, la incidencia de edición de esta primera publicación impresa es sensible en la "ubicación" del texto como anexo documental. Como sintetizó Anne More: "In no small part due to Irving Leonard's early editions, Sigüenza's letter remains the most analyzed document of the riot" (2013:160) ["En no menor medida gracias a las primeras ediciones de Irving Leonard, la carta de Sigüenza sigue siendo el documento más analizado del motín."] Pero es justamente este "valor documento" de la crónica del novohispano el que, desde entonces, no ha perdido vigencia, no solo ecdótica sino críticamente, desplazando la preocupación de la escritura (aquel "no se le añada ni se le quite ni una palabra") por la consideración de sus noticias. Si, como señala Mbembe (2020), la diferencia entre un documento y un archivo radica en el "estatus" de este último, en "el relato que hace posible" el archivo y que lo distingue de una mera pieza de información, cierto es que desde su primera impresión Alboroto y motín ha hecho posible -y privilegiado- el relato histórico, integrándose decisivamente a dicho archivo como "fuente" de lo sucedido, actuado y dicho. Y aunque no se ha dejado de señalar que, siendo "uno de los más detallados y vivaces" (Silva Prada, 2007: 73) no es el único relato ni el más importante, y que incluso ciertas frases y secuencias "parecen modificadas por la imaginación literaria del autor" (337) o por su "estilo [que] es más barroco, más elipsoidal y más literario" (334), no por esto ha abandonado ese "lugar anexo" de la historia, archivo y relato. Así, la crónica de Sigüenza ha informado un evento prácticamente sin levantar sospecha sobre su propio carácter informe, ese que igualmente no ha dejado de notarse, ya por su vivacidad o imaginación, ya por su inusual extensión y -por momentos- difusa intención. Y aunque probablemente en esto radique el que su versión -aun siéndolo (y reconociéndolo)- haya vertebrado prácticamente todas las restantes, ofreciéndose como parámetro o summa de los demás y dispersos (o magros) relatos, de todos modos -y gracias a la edición de 1929- su estatuto histórico ha predominado, y desplazado su tenor y valor literarios.

De esto da cuenta, confusa, el "género" que el propio Leonard le asigna: "Se trata, al parecer, de un informe semioficial, hecho posiblemente a petición del virrey" (1984a: 124) [It is, apparently, a semi-official report of the affair, possibly made at the behest of the viceroy 1929: 112] Como se sabe, y como Leonard sabía, el informe que el virrey Conde de Galve expresamente pide (en un decreto del 30 de junio) y fue firmado por Sigüenza el 5 de julio (cfr. Ruiz y Del Piero 2019) dista -en extensión, vivacidad y estilo- enormemente de la "ésta (...) mi carta", la que el novohispano firma el 30 de agosto y dirige al capitán Andrés de Pez. ${ }^{3}$ Y no solo es el destinatario expreso (y la extensión, vivacidad y estilo) lo que cambia sino, como queda dicho, la intención (de dar a la imprenta y "sacar a luz" ese texto) y el destinatario implícito de la carta que -aclara apenas comenzar- "será bien larga" (2018:117): "para que en esa corte y en esos reinos sepan todos con fundamento lo que otros habrán escrito con no tan individuales y ciertas noticias". Sigüenza escribe para esa otra corte y para esos otros reinos (ese otro lector, ese otro mundo) y lo hace, no para informar como han hecho otros, sino para dar fundamento como solo puede hacerlo él: para que sepan todos con fundamento como ninguno. La apuesta es, a todas luces, muy distinta. Cambia el eje y el centro, y doblemente: no escribe para un virrey y sus funcionarios sino para el Rey y su corte; y no escribe para decir lo que otros ya dijeron ni lo que nadie aún ha dicho sino lo que solo él (esa forma, su estilo) puede decir. Esa singularidad y deliberación, que nadie ha pasado por alto en su lectura y que la escritura del texto nos recuerda

3 Si bien en los manuscritos figura -en el incipit e invariablemente- el rango de "almirante" para Andrés de Pez, de la misma forma, tras la firma de Sigüenza y al final de la carta consta -invariablemente- el rango de "capitán”. Sigüenza en 1692 escribe al “capitán” que, al volver de España (donde tramitaba un proyecto de ambos, ligado a la exploración de la Bahía de Pensacola, realizada en 1693), es nombrado "almirante" (cfr. Weddle). La diferencia de rangos -usualmente pasada por alto- señala, en el texto (manuscrito/copiado-impreso), una diferencia de tiempos (y manos) que entre otras cosas vuelve sobre el problema del título (Alboroto y motín de los indios de México) y, puntualmente, sobre si fue o no colocado y elegido por Sigüenza y Góngora (cfr. Sigüenza y Góngora, 2018: 115 nota 1). 
permanentemente, no puede sino extrañar "el parecer" de Leonard. Un parecer que, he aquí el punto, también es deliberado y singular, pues Leonard "lee" (quiere leer) a Sigüenza en otro siglo y otra parte: preanunciando una ilustración remota y una nación en ciernes y en ambos casos ya lejos, o a salvo, de esa opaca "época barroca en el México colonial" (cfr. Leonard 2004): "aún más que la monja poetisa a quien tanto admiraba, él simboliza la transición de la ortodoxia extrema de la América Española del siglo XVII a la creciente heterodoxia del siglo XVIII (...) el fin de la época barroca y el principio de la Edad de la Razón en la América Hispana" (1984b: X y XXIX). La figura de Sigüenza que crítica, coherentemente ilumina sus textos (o algunos) es también la que ecdótica, cohesivamente organiza la edición de sus obras. Y no obstante el texto se resiste y el crítico se resiente: la palabra "semi" (semi-official report) señala exactamente eso, y es el rastro insoslayable -generoso de Leonard- para alcanzar ese grado cero de la escritura o, como dijo Cornejo Polar, el "punto de fricción total" (1994: 26) donde esa carta es-y-no-es lo que parece, es-y-no-es lo que dice ser: una carta, bien larga, sobre un evento, público y sabidísimo. En ese "semi" emerge el "Imperio del Medio" (Latour, 2007: 79) que -como la figura de Sigüenza- es pensable si no se niegan los híbridos y encabalgamientos, ese "Imperio del Medio" donde crecen "los cuasi-objetos" (2007: 86) que como Alboroto y motín todavía hoy señalan, entre otras cosas y con precisión, la orla del tiempo que rodea nuestro presente.

Menos evidente a primera vista, la incidencia de edición de la primera publicación impresa de Alboroto y motín en 1929 como anexo del estudio de Leonard también impacta en la lengua, no inmediatamente en la de Sigüenza y Góngora aunque sí en la de su escritura. Como se dijo, el texto ("Appendix B") aparece traducido al inglés. A diferencia del único otro anexo del libro ("Appendix A": un catálogo de los escritos de Sigüenza) 4 donde los títulos y referencias constan en castellano, Alboroto y motín aparece íntegramente traducido y con un título distinto: "Letter of Don Carlos de Sigüenza to Admiral Pez Recounting The Incidents of de The Corn Riot in Mexico City, june 8, 1692" (1929: 210). No solo llama la atención que, a diferencia del resto, no se indique en el catálogo la fuente de este texto sino que, al consignarlo, se lo hace de otra manera: "Alboroto y motín de los indios de Mexco. Copia de Carta de D. Carlos de Sigüenza y Góngora, cosmógrapho del Rey en la $\mathrm{N}^{\mathrm{a}}$ Españ Cathedratico de Mathematicas de la Rl Univd. y Capellán mayor del Hospital Rl del Amor de Dios de la Ciudad con q le da razon al Almirante Don Andres de Pez del Tumulto" (1929: 208). Un título incluso distinto del que, 3 años después, el propio Leonard dará al texto cuando lo publique en castellano: Alboroto y motín de México del 8 de junio de 1692. Relación de Don Carlos de Sigüenza y Góngora en una carta dirigida al almirante Don Andrés de Pez (México, Talleres Gráficos del Museo Nacional de Arqueología, Historia y Etnografía, 1932). En ambos casos o de todos modos, son "los indios" lo que Leonard parece resistirse a reconocer en los "titulares" del acontecimiento. Y sin embargo no es esto lo más significativo, en términos de lengua (cfr. Meschonnic 2009), sino el hecho de que en 1929 -desde 1929- el texto es seccionado o fragmentado utilizando subtítulos que, aunque se aclara en nota al pie ("The inserted captions are those of the translator" 1929: 211), nunca abandonarán sus ediciones. El problema, en términos de lengua, no está en el título y sus variantes sino, definitivamente, en los subtítulos y su invariancia. Alboroto y motín, como texto impreso, es también un texto subtitulado. La naturalización o invisibilización crítica de esta cuestión no remite, como podría pensarse, a su primera impresión (traducida) pues allí se aclara no sólo la intervención del traductor sino la función académica y didáctica de la misma, en tanto la fragmentación de la carta facilita su uso (auxiliar) y en tanto estamos ante un estudio -más bio que gráfico- de la figura de Sigüenza. La

4 La traducción al castellano del libro de Leonard (cfr. 1984a) incorpora otros documentos como anexos (C, CH y D) que no figuran en la edición en inglés de 1929. 
naturalización o invisibilización crítica de esta cuestión permite, en todo caso y una vez más, leer -continuar leyendo-Alboroto y motín como un apéndice, anexo ahora no solo de otra historia sino también de otra lengua, ambas ecdóticamente esquivas.

Ya no se trata solo de una carta que, siendo "bien larga", será regularmente abreviada o doblada; sino de una lengua que así, justamente así, no podrá hacer historia con "voz entera": la historia Alboroto y motín como texto subtitulado no puede oírse sino como "voz partida". Como un long play del que solo pudiéramos escuchar sus éxitos en la radio, como una ópera de la que debiéramos imaginar su trama solo partiendo de sus arias, Alboroto y motín retacea desde 1929 su larga crónica. Ese ritmo sin escansión, ese fundamento sin par, esas tan individuales y ciertas y compendiadas y varias noticias, ese largo aliento del relato queda-desde 1929-reducido a sus partes, reducido a dar parte..$^{5} \mathrm{La}$ voz del texto es lo que cambia de lengua en 1929 no tanto sus palabras, que poco después recuperan (con variantes) su idioma. Esa tan deliberada y singular intención -"la subjetivación máxima de un sistema de discurso" (Meschonnic, 2009: 36)- que decide hacer bien larga su carta para que pueda, incomparable, escucharse su voz, escucharse esa voz, escucharse allá lejos esa voz que ha estado bien cerca de lo que dice, en parte se pierde desmembrada en 1929. Y llama la atención no se haya reparado, alguna vez, si no en la rareza -ya por su carácter periodístico ("El virrey busca medidas preventivas", "Nuevas lluvias y eclipse solar" "Se inquieta el pueblo") ya por su extravagancia lisa y llana ("Sigüenza sirve de ingeniero", "Sigüenza, testigo del alboroto", "Intervención de Don Carlos")- al menos en la "función", o cuál sería, de muchos de los subtítulos y, naturalmente, en el "efecto" que sobre la lectura producen. La peculiaridad, por otra parte, de las voces en el texto -algo que nadie ha dejado de notar-y "ese amenazante palabrerío fuera de lugar" (Zanetti, 2000: 390) que se convierte en protagonista del conflicto convocan, en todo caso, al poeta que es y fue Sigüenza y-como dirá luego Emerson- dan a pensar que "el lenguaje es los archivos de la historia y (...) una suerte de tumba de las musas" y que, si persiste el poeta en su lengua, será -como persigue y dice Alboroto y motín- "propietario donde otros solo son arrendatarios" (2016: 36 y 50).

Decía Henri Michaux viajando por Asia que si es difícil juzgar una ópera por el libreto y una canción por su letra, mucho más juzgar a Homero o el Ramayana solo leyéndolos. "Pero si uno oye cantar esas mismas partes, todo lo que era largo es precisamente "lo que cuenta"' (1985: 85-86). Difícil es pensar que, de aquí a trescientos o cuatrocientos años, Operación Masacre de Rodolfo Walsh sea leído únicamente como fuente de unos fusilamientos en un basural de Buenos Aires o que Slaughterhouse-Five de Kurt Vonnegut sea estudiado como parte de los testimonios de los bombardeos de Dresde o que Las malas de Camila Sosa Villada y Loco Afán de Pedro Lemebel solo funjan de archivo insoslayable para una seria historia del travestismo en América del Sur. No obstante muchas veces, exactamente eso parece haber ocurrido con Alboroto y motín de los indios de México de Carlos de Sigüenza y Góngora, más aún cuando se atiende a sus ediciones y a los textos críticos que -indesligables de estas- se ocupan de él. Tarea decisiva, quizá entonces, de la crítica y la ecdótica sea no solo oír a los muertos con los ojos sino ver con el oído todo lo que aún vive escrito, todo lo que canta en la letra y orla nuestro presente.

5 En los "Criterios de esta edición" de Seis Obras Leonard y Bryant anotan: "Como el periodo barroco solía ser excesivamente largo, en pocas ocasiones hemos optado por hacer dos frases en lugar de una.” (1984b: XXXII). 


\section{Bibliografía}

»Altschul, N. (2006). Un acercamiento cultural a la edición de textos medievales: método y mentalidad nacional en Alemania, Francia y España. Neophilologus 90: 383-399.

» Barthes, R. (1970). Introducción al análisis estructural de los relatos. En AA.VV. Análisis estructural del relato, pp. 9-44. Dorriots, B. (trad.). Buenos Aires: Tiempo Contemporáneo.

»Burrus, E. J. (1959). Clavigero and the Lost Siguenza y Góngora Manuscripts. Estudios de Cultura Náhuatl I: 59-90.

»Cristóbal, V. (1992). Introducción. En Virgilio, Eneida, pp. 11-130. Madrid: Gredos.

»Contini, G. (1986). Breviario di ecdótica. Milán/Nápoles: Riccardo Ricciardi.

"Cornejo Polar, A. (1994). Escribir en el aire. Lima: Horizonte.

"Cruz, sor J. de la (2014). Nocturna, mas no funesta. Ruiz, F. y Fumigalli, C. (ed. y notas). Buenos Aires: Corregidor.

"Emerson, R. W. (2016). El poeta. En El poeta y otros ensayos, pp. 19-51. Vidagañ Murgui, F. (trad.). Buenos Aires: Buenos Aires Poetry.

»Florencia, F. de (1685). La milagrosa invención de un tesoro escondido en un campo que halló un venturoso cacique y que escondió en su casa para gozarlo a solas, patente ya en el Santuario de los Remedios en su admirable imagen de Nuestra Señora... México: María de Benavides viuda de Ribera.

» Foucault, M. (2015). La arqueología del saber. Garzón del Camino, A. (trad.). Buenos Aires: Siglo XXI.

» Foucault, M. (1992). Nietzsche, la Genealogía, la Historia. En Microfísica del poder, pp. 7-32. Varela, J. y Álvarez-Uría, F. (trads.). Madrid: La Piqueta.

» Fumagalli, C. (2021). La materialidad del libro en España y Nueva España (siglo XVII-XVIII). Un problema (crítico) literario. En Lima, S. y Facundo Ruiz, F. (orgs.). Barroco americano: mapas para uma literatura crítica. Natal: Edufrn [en prensa].

»Funes, L. (1983). La distinción entre texto y manuscrito. Observaciones sobre crítica textual a propósito de una reciente edición del Libro de la Montería de Alfonso XI, Incipit 3, 25-51.

»Garcilaso de la Vega, I. (2004). Comentarios reales. Araníbar, C. (ed., pról., índice analítico y glosario). México: Fondo de Cultura Económica

» Gracián, B. (1943). Agudeza y arte de ingenio. Buenos Aires: Poblet.

» Guzmán y Córdova, Sebastián de (1690). „Prólogo a quien leyere“. En Carlos de Sigüenza y Góngora, Libra astronomica y philosophica. México: Viuda de Bernardo Calderón, s/f. Edición digital: Alicante, Biblioteca Virtual Miguel de Cervantes, 2005.

» Latour, B. (2007). Nunca fuimos modernos. Goldstein, V. (trad.). Buenos Aires: Siglo XXI.

» Leonard, I. A. (1929). Don Carlos de Sigüenza y Góngora: A Mexican Savant of the Seventeenth Century. Berkeley, University of California Press. 
》 Leonard, I. A. (1984a). Don Carlos de Sigüenza y Góngora. Un sabio mexicano del siglo XVII. Utrilla, J. J. (trad.). México: Fondo de Cultura Económica.

»Leonard, I. A. (1984b). Prólogo y Criterios de esta edición. En Carlos de Sigüenza y Góngora, Seis Obras. Caracas: Ayacucho, ix-xxxiii.

»Leonard, I. A. (2004). La época barroca en el México colonial. Ezcurdia, A. (trad.). México: Fondo de Cultura Económica.

» Lezama Lima, J. (1993). La expresión americana. México: Fondo de Cultura Económica.

» Mbembé, A. (2020). El poder del archivo y sus límites. Fumagalli, C. (traad.). Orbis Tertius 31.

» Marcus, G. (1993). Rastros de carmín. Alou, D. (trad.). Barcelona: Anagrama.

» Meschonnic. H. (2009). Ética y política del traducir. Savino, H. (trad.). Buenos Aires: Leviatán.

" Michaux, H. (1985). Un bárbaro en Asia. Borges, J. L. (trad.). Madrid: Hyspamérica.

"More, A. (2013). Baroque Sovereignty. Carlos de Siguenza y Gongora and the Creole Archive of Colonial Mexico. Filadelfia: University of Pennsylvania Press.

»Moreno, M. (2018). Oración. Buenos Aires: Random House.

»Ruiz, F. y Del Piero, G. (2019). Barroco y res publica. Los indios y el centro de la ciudad según Sigüenza y Góngora. Líneas 12.

»Sigüenza y Góngora, C. de (1690). Libra astronomica y philosophica... México: Viuda de Bernardo Calderón.

»Sigüenza y Góngora, C. de (1995 [1684]). Parayso occidental plantado y cultivado por la liberal y benéfica mano de los muy cathólicos y poderosos reyes de España nuestros señores en su Real Convento de Jesús María de México México, UNAMCentro de Estudios de Historia de México/Condumex (edición facsimilar).

» Sigüenza y Góngora, C. de (2018). Mínimas multitudes. Ruiz, F. y del Piero, G. (ed. y notas). Buenos Aires: Corregidor.

"Silva Prada, N. (2007). La política de una rebelión: los indios frente al tumulto de 1692 en la Ciudad de México. México: El Colegio de México.

» Süssekind, F. (2000). De la sensación de no estar del todo. En Amante, A. y Garramuño, F. (selec., trad. y pról.). Absurdo Brasil, pp. 19-43. Buenos Aires: Biblos.

»Trabulse, E. (1988). Los manuscritos perdidos de Sigüenza y Góngora. México: Colegio de México.

»Walsh, R. (2006). Operación masacre. Buenos Aires: De La Flor.

»Weddle, R. S. (s/f). Pez y Malzarraga, Andrés de. Handbook of Texas Online. https://www.tshaonline.org/handbook/entries/pez-y-malzarraga-andres-de (consulta 05/11/2020)

»Zanetti, S. (2000). El letrado y la plebe: Alboroto y motín de México de 1692 de Carlos de Sigüenza y Góngora. En Romanos, M. (coord.); Calvo, F. y Romanos, M. (eds.), Lecturas críticas de textos hispánicos: estudios de literatura española Siglo de Oro, Vol. 2, pp. 389-396. Buenos Aires: Eudeba-Instituto de Filología y Literaturas Hispánicas “Dr.Amado Alonso”.

»Zanetti, S. (1987). La lectura en la literatura latinoamericana. Filología 2: 175-189. 